\title{
Pain in Chronic Inflammatory Demyelinating Polyradiculoneuropathy: A Systematic Review and Meta-Analysis
}

\author{
Athena Michaelides - Robert D. M. Hadden • Ptolemaios G. Sarrigiannis • \\ Marios Hadjivassiliou • Panagiotis Zis (D)
}

Received: April 29, 2019 / Published online: June 14, 2019

(C) The Author(s) 2019

\begin{abstract}
Introduction: Although chronic inflammatory demyelinating polyradiculoneuropathy (CIDP) predominantly affects large myelinated fibers, many patients have pain. The aim of this paper is to systematically review the current literature regarding CIDP with a particular focus on epidemiological and clinical characteristics of painful CIDP.
\end{abstract}

Methods: A systematic literature search was conducted on PubMed database.

Results: Our search strategy identified 146 articles. Thirty-eight papers, reporting on 991 patients, met the inclusion criteria and were

Enhanced Digital Features To view enhanced digital features for this article go to https://doi.org/10.6084/ m9.figshare.8209862.

A. Michaelides

Medical School, University of Nicosia, Nicosia, Cyprus

R. D. M. Hadden

Department of Neurology, King's College Hospital, London, UK

P. G. Sarrigiannis - M. Hadjivassiliou · P. Zis ( $₫)$ Academic Department of Neurosciences, Sheffield Teaching Hospitals NHS Foundation Trust, Sheffield, UK

e-mail: takiszis@gmail.com

P. Zis

Medical School, University of Cyprus, Nicosia, Cyprus used for this review. The pooled estimate of the prevalence of pain at any point within the course of CIDP was $46 \%$ (95\% CI $36-57 \%$ ). Immune treatment of CIDP might be adequate as monotherapy for the management of pain. Treatment specific to pain currently shows effectiveness as adjuvant treatment when CIDP is treated and pain persists.

Conclusions: Pain in CIDP is an underexplored field. Future research should focus on the natural history, phenomenology, and management of pain in CIDP.

Keywords: Chronic inflammatory demyelinating polyradiculoneuropathy; CIDP; Neuropathy; Pain; Treatment

\section{INTRODUCTION}

Pain as defined by The International Association for the Study of Pain (IASP) is an unpleasant sensory and emotional experience associated with actual or potential tissue damage [1]. Since it is a subjective, vague, and multivalent experience that is influenced by cultural, social, personal, and emotional phenomena, it is difficult to measure with precision. Pain is a common and disabling symptom that is prevalent in patients suffering from peripheral neuropathy (PN). Pain adds to the burden of the disease and has an additional and 
significant negative impact to patients' quality of life $[2,3]$.

Contrary to the misconception that painful $\mathrm{PN}$ is secondary to diabetes or pre-diabetes, peripheral neuropathic pain (PNP) is also prevalent in cryptogenic or chronic idiopathic axonal polyneuropathy (CIAP) [4] and PN of other etiologies, including alcohol-induced [5], platin-induced [6], related to gluten sensitivity [7], related to Parkinson's disease [8-10], and paraneoplastic $[11,12]$. PNP can be present in acute and subacute immune-mediated neuropathies. The most common acute neuropathy presenting with pain is Guillain-Barré syndrome (GBS) with an estimated pain prevalence of $35 \%$ [13].

Chronic inflammatory demyelinating polyradiculoneuropathy (CIDP) is a chronic neuropathy of supposed immune origin [14]. The classic presentation of CIDP includes sensory and motor impairment in the distal and proximal segments of all limbs evolving over more than 8 weeks.

The aim of this paper is to systematically review the current literature in order to establish the prevalence of pain in CIDP and describe its phenomenology and its response to treatment.

\section{METHODS}

\section{Literature Search Strategy}

A systematic computer-based literature search was conducted on the PubMed database on May 23, 2019. For the search, two Medical Subject Headings (MeSH) were used in either the abstract or the title. The search was conducted as Term A and Term B. Term A was "chronic acquired demyelinating" or "chronic inflammatory demyelinating" or "chronic idiopathic demyelinating" or "CIDP" and Term C was "pain" or "painful". The search was conducted as "Term A" and "Term B". Articles were limited to the human species, English language, and full text availability.

The reference lists of the identified articles were scanned for further papers, which may fall within the scope of this review and were included where appropriate.

\section{Inclusion and Exclusion Criteria}

To be included, the articles had to meet the following criteria:

1. Be single case reports, case series, prospective or retrospective cohort studies, or clinical trials of patients with a confirmed diagnosis of classic CIDP or any of the following variants:
(a) Distal acquired demyelinating sym- metric (DADS) neuropathy.
(b) Multifocal demyelinating sensory and motor (MADSAM) neuropathy or chronic multifocal demyelinating neu- ropathy or Lewis-Sumner syndrome (LSS).
(c) CIDP with focal presentation.
(d) Pure sensory CIDP or chronic sensory demyelinating neuropathy (CSDN) or chronic immune sensory polyradicu- lopathy (CISP).
(e) Pure motor CIDP.

2. Pain presumed to be caused by the CIDP itself, with no evidence of alternative cause for the pain.

3. Involve human adult subjects.

Papers were excluded when they were:

1. Book chapters, reviews, letters to the editor, and editorials.

2. Papers referring to neuropathies that present like CIDP but did not meet the electrodiagnostic criteria for CIDP according to the European Federation of Neurological Societies/Peripheral Nerve Societies (EFNS/ PNS) criteria, or the American Academy of Neurology (AAN) Ad Hoc Subcommittee Electrodiagnostic Criteria for chronic inflammatory demyelinating polyneuropathy.

3. Papers in which insufficient clinical information about pain was provided (e.g., economic studies, histopathological studies, etc.) 


\section{Data Extraction}

Data were extracted from each study using a structured framework on Microsoft Excel. This included the article title, type of study, year of publication, country, number of subjects, gender, age, type of CIDP, pain characteristics, treatment type, and treatment effectiveness.

\section{Statistical Analyses}

A database was developed using the IBM SPSS Statistics (version 25.0 for Mac). Frequencies and descriptive statistics were calculated for each variable.

Meta-analysis of the pooled proportions was conducted in $\mathrm{R}$ language [15] using the default settings of the 'metaprop' package. The outcome of interest was the proportion of CIDP patients experiencing pain. Data were analyzed using a random effects model.

\section{Compliance with Ethics Guidelines}

This paper is based on studies that were previously conducted. It does not involve any new studies of or experimentation on human or animal subjects by the aforementioned authors.

\section{RESULTS}

\section{Search Results}

The search strategy resulted in the identification of 146 papers. After the eligibility assessment, 129 papers were excluded. A total of 17 papers met the inclusion criteria and were included. After scanning the reference lists of the included papers, another 21 papers were identified that were deemed eligible and were included in the review. This gave a total of 38 papers that were published between 1982 and 2019 [16-53]. Figure 1 illustrates the study selection process.

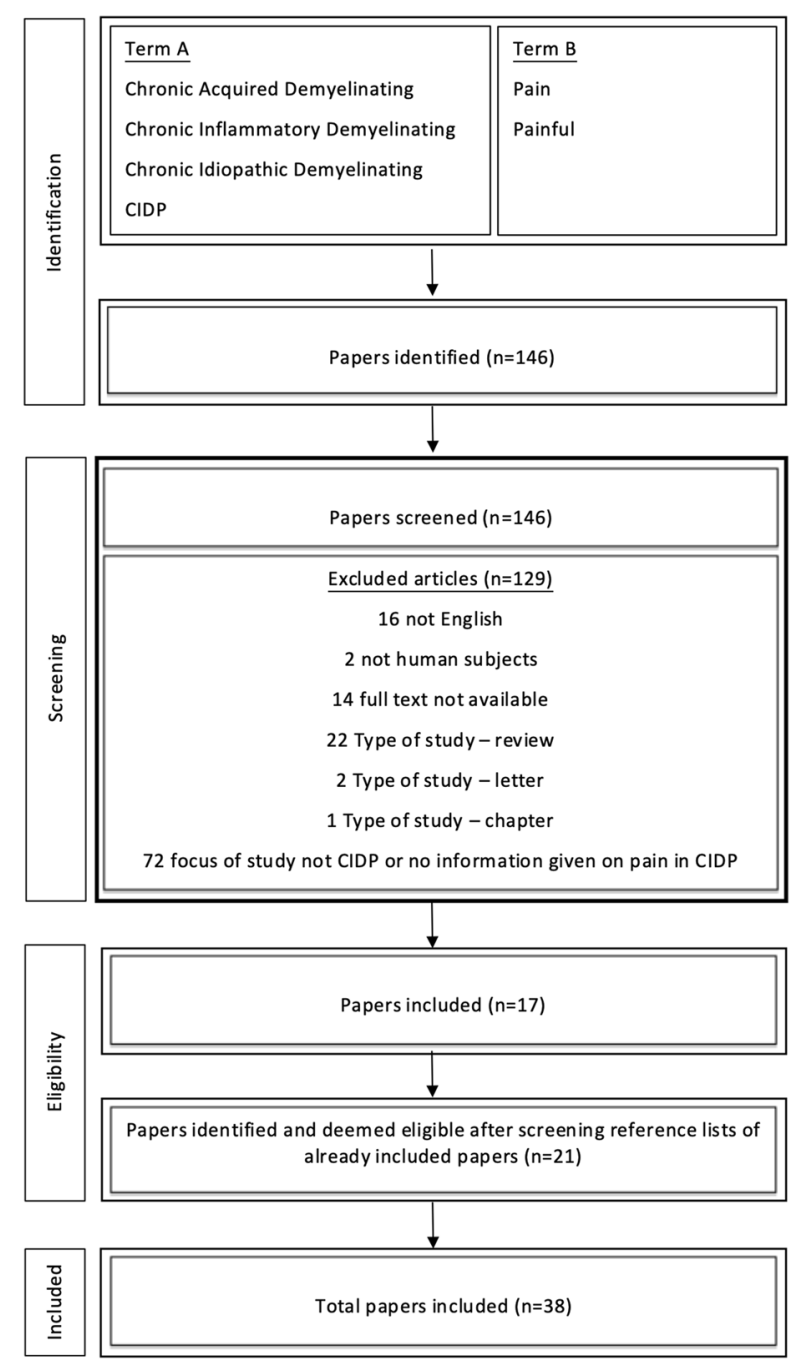

Fig. 1 PRISMA chart

\section{Patient Characteristics}

In total, the included papers reported on 991 patients with a confirmed diagnosis of CIDP (62\% males, mean age, 49.6 years) according to the EFNS/PNS or AAN criteria. Of all patients, 755 had typical CIDP (76\%) and 236 had variants (24\%). Amongst those with CIDP variants, $53(23 \%)$ had a pure motor type, 99 (42\%) had a pure sensory type, 12 (5\%) had focal CIDP, 12 (5\%) had DADS, and 60 (25\%) had the LSS/ MADSAM variant. The mean duration of disease was 2.6 years. When reported, the course of the disease was classified as relapsing-remitting in 
Table 1 Descriptive of studies included in the review

\begin{tabular}{ll}
\hline Parameter & Value \\
\hline Number of papers* & 38 \\
Type of paper & \\
Case series/cohort study & 28 \\
Single case report & 8 \\
Case-controlled study & 2 \\
Total number of unique patients & 991 \\
CIDP type & \\
Typical (\%) & $755(76)$ \\
Pure motor (\%) & $53(5)$ \\
Pure sensory (\%) & $99(10)$ \\
MADSAM/LSS (\%) & $60(6)$ \\
DADS (\%) & $12(1)$ \\
Focal (\%) & $12(1)$ \\
Mean number of patients per study & $26.8(51.7)$ \\
(SD) & $3: 2$ \\
Male:female & 49.6 \\
Mean age, in years & 2.6 \\
Pain present at any point & $46 \%(95 \%$ CI \\
\hline
\end{tabular}

$43 \%$ of the patients, and chronic-progressive in $57 \%$.

Table 1 summarizes the characteristics of the included papers and the patients that were studied.

\section{Prevalence and Distribution of Pain}

Based on the 38 papers reporting on 991 patients, the pooled estimate of the prevalence of pain at any point within the course of the disease was 46\% (95\% CI 36-57\%). Due to a lack of specific pain figures, it was not possible to extrapolate the prevalence of pain in each CIDP variant.

For the majority of patients, the phenotype of pain was not characterized in detail. Amongst the patients for whom the phenotype of pain was described $(n=22), 15(68 \%)$ experienced only proximal/radicular type of neuropathic pain (including lower back pain), three (14\%) experienced only distal peripheral neuropathic pain, and four (18\%) a combination of proximal/radicular and distal neuropathic pain [18, 24-26, 28-33, 35, 37, 40, 41, 44, 45, 47, 49].

None of the papers included in this review reported on a patient where pain was an isolated symptom. Pain always coexisted with other CIDP features, the most prominent being weakness (reported by $85 \%$ of painful CIDP patients) $[17-20,23,24,26-31,33-35,37$, $38,40-42,45-50,52]$ followed by numbness (reported by $75 \%$ of painful CIDP patients) $[17,19,21-39,41-50,52]$.

\section{Immune Treatment for CIDP and Effect on Pain}

The majority of patients in the included papers received immune treatment for their CIDP (93\%). The reasons for not having treatment were mainly a lack of consent to have the treatment as well as having very mild symptoms. Amongst the treated group, about twothirds were on monotherapy and one-third on combined therapy. Monotherapy patients used intravenous immunoglobulins (IVIG) more often $(71 \%)$, followed by intravenous or oral steroids (26\%) and plasma exchange (3\%).

No robust data regarding the effect of treatment for pain in CIDP were available. The effectiveness of CIDP treatment in pain was clearly reported only in 46 patients [17-19, 23-26, 28, 30-35, 37, 41-45, 47-49]. Of those, in 41 patients (89\%), treatment for CIDP had reduced pain. Amongst these patients, 17 were in response to monotherapy (ten received steroids and seven received IVIG) and 24 to combined therapy.

\section{Treatment for Pain in the Context of CIPD}

Limited information is available about management specific to pain. Of the 38 included papers, only in four papers the pain course and treatment were described [17, 24, 43, 48]. 
Boukhris et al. described pain presentation and management in five patients with CIDP [24]; a 74-year-old female with radicular pain in the lower limbs was treated with gabapentin, amitriptyline, carbamazepine, ketamine, and IV corticosteroids but had no response; a 75-year-old female with radicular pain showed no improvement after receiving gabapentin and amitriptyline but was treated successfully with high-dose IV methylprednisolone; a 71-year-old female with distal neuropathic pain in the lower limbs received only symptomatic treatment with amitriptyline to which she showed modest improvement; a 76-year-old male with radicular pain was given clonazepam with no improvement but showed marked response after IVIg; a 56-year-old male with distal neuropathic pain in the lower limbs was treated with amitriptyline, gabapentin, carbamazepine, lamotrigine, sodium valproate, and morphine sulfate with no effect, but improved after oral steroids [24].

Oh et al. described three patients that all had a diagnosis of painful CIDP presenting as a pure sensory neuropathy: in one patient, pain was effectively managed with opioids whereas in the other two, pain was effectively managed with a combination of opioids and amitriptyline [43].

Liewluck et al. described two patients with painful DADS neuropathy: a 35-year-old female who was initially put on IV methylprednisolone and opioids and only after duloxetine was added the pain improved; and a 58-year-old female who reported pain relief after being initially on IV methylprednisolone and opioids and subsequently on a combination of gabapentin and amitriptyline [17].

Shah et al. described a middle-aged male patient who had suffered from sensory CIDP for over 20 years who was stable on oral steroids and methotrexate. His pain was successfully treated with gabapentin [48].

From these papers, it is clear that patients with peripheral neuropathic pain, because of undiagnosed and untreated CIDP, did find symptomatic relief when they were diagnosed and subsequently treated for CIDP. In the majority of cases, use of medication specific to neuropathic pain was effective only as adjuvant to immunotherapy when residual neuropathic pain was present.

It is important to highlight that no randomized controlled trials for the management of pain in CIDP have been conducted to date. Therefore, the evidence for the management of pain in CIDP is still weak, as only case series and case reports are currently available.

\section{Natural History of Pain in CIDP}

Bjelica et al. reported details of the natural history of pain in 74 patients with CIDP over a period of 12 months, diagnosed based on the IASP criteria and confirmed with the painDETECT questionnaire [54]. The mean disease duration at baseline was 7 years.

At baseline, 14 patients were pain-free being on treatment for pain (eight on pregabalin, four on gabapentin, and two on amitriptyline), five patients were in pain despite being on treatment (all receiving pregabalin), eight patients were in pain but not on treatment, and 47 were pain free [53].

All 47 patients that were pain and medication-free at baseline, remained pain-free at follow-up but four (9\%) had to start taking antineuralgics.

The majority of patients $(93 \%, n=14)$ that were pain-free but on medication at baseline remained pain-free at follow-up. Of those, five (38\%) managed to discontinue their anti-neuralgics without developing pain, whereas eight $(62 \%)$ continued to receive the same monotherapy.

Three out of five patients that were in pain despite being on pregabalin were pain-free at follow-up and managed to discontinue their anti-neuralgics. In one patient, pain persisted but was of less intensity, whereas in another patient, pain persisted despite switching pregabalin to gabapentin.

Four out of eight patients that were in pain but not on medication at baseline were pain and medication-free at follow-up. The other four patients were pain-free at follow-up-two being on pregabalin, and two on a pregabalin and amitriptyline combination. 


\section{CONCLUSIONS}

This systematic review indicates the following key points:

1. Neuropathic pain is a common symptom in patients with CIDP.

2. Although pain can be within the first manifestations of CIDP, it is almost always accompanied by other symptoms, especially weakness.

3. Despite the high prevalence of pain, data of the natural history and phenomenology of pain in the context of CIDP are lacking. Future studies should focus on describing the intensity and characteristics of pain in CIDP using measures such as the visual analogue scale (VAS), the DN4 questionnaire [55], or the painDETECT questionnaire [54] in order to shed light on the underlying pathophysiological mechanisms.

4. Although CIDP is a disease of the peripheral nervous system, there have been many reports of involvement of the central nervous system too [56]. The pathogenesis of pain in patients with CIDP has not been discussed in the papers included in this review. Although the pain clearly relates to the inflammation of the peripheral nerves and the spinal roots, whether a central component is implicated in the increased perception of pain needs to be studied in the future.

5. Treatment of CIDP (i.e., IVIG or steroids) might be adequate as monotherapy for the management of pain. This highlights the need for a complete diagnostic work-up in all patients who present with peripheral neuropathic pain. Diagnosis of milder forms of painful CIDP with minimal motor involvement might alter the strategy in the management of pain.

6. Treatment specific to neuropathic pain currently shows effectiveness as adjuvant treatment when CIDP is treated and pain persists. However, this is only based on isolated cases and case series and therefore controlled studies for the management of pain in CIDP are lacking.

\section{LIMITATIONS}

There was much heterogeneity between studies included in this review with regard to the authors' definitions of pain and its phenomenology. No studies identified by this review discussed the pathogenesis of pain in CIDP. Finally, a single database was utilized to conduct the literature search for this study. This may have caused some studies to be excluded. However, the authors checked the reference lists of every included study to identify additional seminal publications.

\section{ACKNOWLEDGEMENTS}

Funding. No funding or sponsorship was received for this study or publication of this article.

Authorship. All named authors meet the International Committee of Medical Journal Editors (ICMJE) criteria for authorship for this article, take responsibility for the integrity of the work as a whole, and have given their approval for this version to be published.

Disclosures. Robert D. M. Hadden has received personal and departmental payments from CSL Behring and Grifols. The remaining authors Athena Michaelides, Ptolemaios G. Sarrigiannis, Marios Hadjivassiliou, and Panagiotis Zis have nothing to disclose.

Compliance with Ethics Guidelines. This paper is based on studies that were previously conducted. It does not involve any new studies of or experimentation on human or animal subjects by the aforementioned authors.

Data Availability. The datasets generated and/or analyzed during the current study are available from the corresponding author on reasonable request.

Open Access. This article is distributed under the terms of the Creative Commons Attribution-NonCommercial 4.0 International 
License (http://creativecommons.org/licenses/ by-nc/4.0/), which permits any noncommercial use, distribution, and reproduction in any medium, provided you give appropriate credit to the original author(s) and the source, provide a link to the Creative Commons license, and indicate if changes were made.

\section{REFERENCES}

1. IASP (International Association for the Study of Pain) Terminology. Part III: pain terms, a current list with definitions and notes on usage. Classification of chronic pain, 2nd edn. In: Merskey $\mathrm{H}$, Bogduk N, editors. IASP task force on taxonomy. Seattle: IASP Press; C1994. p. 209-214. https:// www.iasp-pain.org/terminology?navItemNumber= 576\#Pain. Accessed 11 June 2019.

2. Zis P, Sarrigiannis PG, Rao DG, Hadjivassiliou M. Quality of life in patients with gluten neuropathy: a case-controlled study. Nutrients. 2018;10(6):E662. https://doi.org/10.3390/nu10060662.

3. Zis P, Sarrigiannis PG, Rao DG, Hewamadduma C, Hadjivassiliou M. Chronic idiopathic axonal polyneuropathy: prevalence of pain and impact on quality of life. Brain Behav. 2019;9(1):e01171. https://doi.org/10.1002/brb3.1171.

4. Zis P, Sarrigiannis PG, Rao DG, Hewamadduma C, Hadjivassiliou M. Chronic idiopathic axonal polyneuropathy: a systematic review. J Neurol. 2016;263(10):1903-10.

5. Julian T, Glascow N, Syeed R, Zis P. Alcohol-related peripheral neuropathy: a systematic review and meta-analysis. J Neurol. 2018. https://doi.org/10. 1007/s00415-018-9123-1.

6. Brozou V, Vadalouca A, Zis P. Pain in platin-induced neuropathies: a systematic review and metaanalysis. Pain Ther. 2018;7(1):105-19.

7. Zis P, Sarrigiannis PG, Rao DG, Hadjivassiliou M. Gluten neuropathy: prevalence of neuropathic pain and the role of gluten-free diet. J Neurol. 2018;265(10):2231-6.

8. Adewusi JK, Hadjivassiliou M, Vinagre-Aragón A, $\mathrm{O}^{\prime}$ Connor KR, Khan A, Grünewald RA, Zis P. Peripheral neuropathic pain in idiopathic Parkinson's disease: prevalence and impact on quality of life; a case-controlled study. J Neurol Sci. 2018;15(392):3-7.
9. Adewusi JK, Hadjivassiliou M, Vinagre-Aragón A, O'Connor KR, Khan A, Grünewald RA, Zis P. Sensory neuropathic symptoms in idiopathic Parkinson's disease: prevalence and impact on quality of life. Acta Neurol Belg. 2018;118(3):445-50.

10. Zis P, Grünewald RA, Chaudhuri RK, Hadjivassiliou M. Peripheral neuropathy in idiopathic Parkinson's disease: a systematic review. J Neurol Sci. 2017;15(378):204-9.

11. Zis P, Paladini A, Piroli A, McHugh PC, Varrassi G, Hadjivassiliou M. Pain as a first manifestation of paraneoplastic neuropathies: a systematic review and meta-analysis. Pain Ther. 2017;6(2):143-51.

12. Zis P, Varrassi G. Painful peripheral neuropathy and cancer. Pain Ther. 2017;6(2):115-6.

13. Artemiadis AK, Zis P. Neuropathic pain in acute and subacute neuropathies: a systematic review. Pain Physician. 2018;21(2):111-20.

14. Vallat JM, Sommer C, Magy L. Chronic inflammatory demyelinating polyradiculoneuropathy: diagnostic and therapeutic challenges for a treatable condition. Lancet Neurol. 2010;9(4):402-12.

15. R Core Team (2013). R: A language and environment for statistical computing. Vienna: R Foundation for Statistical Computing. http://www.Rproject.org/. Accessed 11 June 2019.

16. Kacar A, Bjelica B, Bozovic I, Peric S, Nikolic A, Cobeljic M, et al. Neuromuscular disease-specific questionnaire to assess quality of life in patients with chronic inflammatory demyelinating polyradiculoneuropathy. J Peripher Nerv Syst. 2018;23(1):11-6.

17. Liewluck T, Engelstad JK, Mauermann ML. Immunotherapy-responsive allodynia due to distal acquired demyelinating symmetric (DADS) neuropathy. Muscle Nerve. 2016;54(5):973-7.

18. Bäumer D, Grant DJ, Knight R, Buckley C, Bennett $\mathrm{D}$, Rinaldi S. CIDP presenting as recurrent severe back pain without weakness or sensory loss. Pract Neurol. 2016;16(6):488-92.

19. Lin K-Y, Wang I-H, Jou J-R, Chu H-J, Wei W, Lee $\mathrm{S}-\mathrm{H}$. Bilateral optic neuritis related to chronic inflammatory demyelinating polyneuropathy. Taiwan J Ophthalmol [Internet]. 2015;5(1):40-3.

20. Kuitwaard K, Hahn AF, Vermeulen M, Venance SL, Van Doorn PA. Intravenous immunoglobulin response in treatment-naïve chronic inflammatory demyelinating polyradiculoneuropathy. J Neurol Neurosurg Psychiatry. 2015;86(12):1331-6. 
21. dos Santos PL, Barreira AA, de Almeida-Ribeiro GAN, Marques Junior W, Silva DMD. Chronic inflammatory demyelinating polyneuropathy: quality of life, sociodemographic profile and physical complaints. Arq Neuropsiquiatr. 2014;72(3):179-83.

22. Nasu S, Misawa S, Sekiguchi Y, Shibuya K, Kanai K, Fujimaki Y, et al. Different neurological and physiological profiles in POEMS syndrome and chronic inflammatory demyelinating polyneuropathy. J Neurol Neurosurg Psychiatry. 2012;83(5):476-9.

23. Rajabally YA, Chavada G. Lewis-Sumner syndrome of pure upper-limb onset: diagnostic, prognostic, and therapeutic features. Muscle Nerve. 2009;39(2):206-20.

24. Boukhris S, Magy L, Khalil M, Sindou P, Vallat JM. Pain as the presenting symptom of chronic inflammatory demyelinating polyradiculoneuropathy (CIDP). J Neurol Sci. 2007;254(1-2):33-8.

25. Boukhris S, Magy L, Gallouedec G, Khalil M, Couratier P, Gil J, et al. Fatigue as the main presenting symptom of chronic inflammatory demyelinating polyradiculoneuropathy: a study of 11 cases. J Peripher Nerv Syst. 2005;10(3):329-37.

26. Pytel P, Rezania K, Soliven B, Frank J, Wollmann R. Chronic inflammatory demyelinating polyradiculoneuropathy (CIDP) with hypertrophic spinal radiculopathy mimicking neurofibromatosis. Acta Neuropathol [Internet]. 2003;105(2):185-8.

27. Gorson Chaudhry V. Polyneuropathy chronic inflammatory demyelinating. Curr Treat Options Neurol. 1999;1(3):251-62.

28. Lewis RA, Sumner AJ, Brown MJ, Asbury AK. Multifocal demyelinating neuropathy with persistent conduction block. Neurology. 1982;32(9):958-64.

29. Gorson K, Ropper AH, Weinberg DH. Upper limb predominant, multifocal chronic inflammatory. Muscle Nerve. 1999;22(6):758-65.

30. Franssen H, Van den Berg LH, Van den Berg-Vos RM, Oh SJ, Wokke JHJ. Multifocal inflammatory demyelinating neuropathy: a distinct clinical entity? Neurology. 2012;55(5):735-42.

31. Misra VP, Walker RWH. Acute-onset painful upper limb multifocal demyelinating motor neuropathy. J Neurol. 2000;247(12):949-54.

32. Viala K, Renié L, Maisonobe T, Béhin A, Neil J, Léger $\mathrm{JM}$, et al. Follow-up study and response to treatment in 23 patients with Lewis-Sumner syndrome. Brain. 2004;127(9):2010-7.

33. de Freitas MRG, Nascimento OJM, Domingues RC, Soares CN, Brito AR. Chronic inflammatory demyelinating polyradiculoneuropathy: two cases with cervical spinal cord compression. Arq Neuropsiquiatr. 2006;63(3a):666-9.

34. Tataroglu C, Ozkul A, Sair A. Chronic inflammatory demyelinating polyneuropathy and respiratory failure due to phrenic nerve involvement. Clinical neuromuscular disease. J Clin Neuromuscul Dis [Internet]. 2010;12(1):42-6.

35. Leitch MM, Sherman WH, Brannagan TH. Distal acquired demyelinating symmetric polyneuropathy progressing to classic chronic inflammatory demyelinating polyneuropathy and response to fludarabine and cyclophosphamide. Muscle Nerve. 2013;47(2):292-6.

36. Ayrignac X, Viala K, Koutlidis RM, Taïeb G, Stojkovic T, Musset L, et al. Sensory chronic inflammatory demyelinating polyneuropathy: an underrecognized entity? Muscle Nerve. 2013;48(5): 727-32.

37. Ram Ayyar D, Bradley WG, Rotta FT, Sussman AT, Shebert RT, Sharma KR. The spectrum of chronic inflammatory demyelinating polyneuropathy. J Neurol Sci. 2002;173(2):129-39.

38. Berger AR, Herskovitz S, Kaplan J. Late motor involvement in cases presenting as "chronic sensory demyelinating polyneuropathy". Muscle Nerve. 1995;18(4):440-4.

39. Dyck PJB, Spinner RJ, Klein CJ, Daube JR, Sinnreich M, Engelstad J. Chronic immune sensory polyradiculopathy: a possibly treatable sensory ataxia. Neurology. 2012;63(9):1662-9.

40. Li Y, Thammongkolchai T, Suhaib O, Katirji B, Termsarasab P. Chronic immune sensorimotor polyradiculopathy (CISMP): report of a case series. Muscle Nerve. 2019;59(6):658-64.

41. Caporale C, Staedler C, Gobbi C, Bassetti C, Uncini A. Chronic inflammatory lumbosacral polyradiculopathy: a regional variant. Muscle Nerve. 2011;44: 833-7. https://doi.org/10.1002/mus.22165.

42. Morrison KE, Davies PTG. Chronic inflammatory demyelinating polyneuropathy presenting with headache and papilledema. Headache. 1999;39(4): 299-300.

43. Oh SJ, Joy JL, Kuruoglu R. "Chronic sensory demyelinating neuropathy": chronic inflammatory demyelinating polyneuropathy presenting as a pure sensory neuropathy. J Neurol Neurosurg Psychiatry. 1992;55(8):677-80.

44. Ginsberg L, Platts AD, Thomas PK. Chronic inflammatory demyelinating polyneuropathy 
mimicking a lumbar spinal stenosis syndrome. J Neurol Neurosurg Psychiatry. 1995;59(2):189-91.

45. King RH, Lecky BR, Schady W, Goulding PJ, Smith CM. Massive nerve root enlargement in chronic inflammatory demyelinating polyneuropathy. J Neurol Neurosurg Psychiatry. 2008;61(6):636-40.

46. McCobe PA, Pollard JD, McLeod JG. Chronic inflammatory demyelinating polyradiculoneuropathy: a clinical and electrophysiological study of 92 cases. Brain. 1987;6:1617-30.

47. Goldstein JM, Parks BJ, Mayer PL, Kim JH, Sze G, Miller RG. Nerve root hypertrophy as the cause of lumbar stenosis in chronic inflammatory demyelinating polyradiculoneuropathy. Muscle Nerve. 1996;19(7):892-6.

48. Shah S, Chandrashekar H, Manji H, Davagnanam I. Cranial nerve, spinal root and plexus hypertrophy in chronic inflammatory demyelinating polyneuropathy. Pract Neurol. 2012;12(1):68-9.

49. Yang F, Thompson EO, Soper JR, McLeod JG, Davies $\mathrm{L}$, Pollard JD, et al. Spinal root and plexus hypertrophy in chronic inflammatory demyelinating polyneuropathy. Brain. 2002;122(7):1383-90.

50. Simmons Z, Albers JW, Bromberg MB, Feldman EL. Presentation and initial clinical course in patients with chronic inflammatory demyelinating polyradiculoneuropathy: comparison of patients without and with monoclonal gammopathy. Neurology. 2012;43(11):2202.

51. Kuitwaard K, Bos-Eyssen ME, Blomkwist-Markens $\mathrm{PH}$, van Doorn PA. Recurrences, vaccinations and long-term symptoms in GBS and CIDP. J Peripher Nerv Syst. 2009;14:310-5.

52. Simmons Z, Wald JJ, Albers JW. Chronic inflammatory demyelinating polyradiculoneuropathy in children: I. Presentation, electrodiagnostic studies, and initial clinical course, with comparison to adults. Muscle Nerve. 1997;20(8):1008-15.

53. Bjelica B, Peric S, Bozovic I, Kacar A, Cobeljic M, Dejanovic I, Stevic Z, Basta I. One-year follow-up study of neuropathic pain in chronic inflammatory demyelinating polyradiculoneuropathy. J Peripher Nerv Syst. 2019. https://doi.org/10.1111/jns.12318 (Epub ahead of print).

54. Freynhagen R, Baron R, Gockel U, Tölle TR. painDETECT: a new screening questionnaire to identify neuropathic components in patients with back pain. Curr Med Res Opin. 2006;22(10):1911-20.

55. Bouhassira D, Attal N, Alchaar H, Boureau F, Brochet B, Bruxelle J, Cunin G, Fermanian J, Ginies P, Grun-Overdyking A, Jafari-Schluep $H$, LantériMinet M, Laurent B, Mick G, Serrie A, Valade D, Vicaut E. Comparison of pain syndromes associated with nervous or somatic lesions and development of a new neuropathic pain diagnostic questionnaire (DN4). Pain. 2005;114(1-2):29-36.

56. Ormerod IE, Waddy HM, Kermode AG, Murray NM, Thomas PK. Involvement of the central nervous system in chronic inflammatory demyelinating polyneuropathy: a clinical, electrophysiological and magnetic resonance imaging study. J Neurol Neurosurg Psychiatry. 1990;53(9):789-93. 